\title{
Is part-time employment beneficial for firm productivity?
}

Citation for published version (APA):

Nelen, A. C., de Grip, A., \& Fouarge, D. (2011). Is part-time employment beneficial for firm productivity? METEOR, Maastricht University School of Business and Economics. METEOR Research Memorandum No. 007 https://doi.org/10.26481/umamet.2011007

Document status and date:

Published: 01/01/2011

DOI:

10.26481/umamet.2011007

Document Version:

Publisher's PDF, also known as Version of record

\section{Please check the document version of this publication:}

- A submitted manuscript is the version of the article upon submission and before peer-review. There can be important differences between the submitted version and the official published version of record.

People interested in the research are advised to contact the author for the final version of the publication, or visit the DOI to the publisher's website.

- The final author version and the galley proof are versions of the publication after peer review.

- The final published version features the final layout of the paper including the volume, issue and page numbers.

Link to publication

\footnotetext{
General rights rights.

- You may freely distribute the URL identifying the publication in the public portal. please follow below link for the End User Agreement:

www.umlib.nl/taverne-license

Take down policy

If you believe that this document breaches copyright please contact us at:

repository@maastrichtuniversity.nl

providing details and we will investigate your claim.
}

Copyright and moral rights for the publications made accessible in the public portal are retained by the authors and/or other copyright owners and it is a condition of accessing publications that users recognise and abide by the legal requirements associated with these

- Users may download and print one copy of any publication from the public portal for the purpose of private study or research.

- You may not further distribute the material or use it for any profit-making activity or commercial gain

If the publication is distributed under the terms of Article $25 \mathrm{fa}$ of the Dutch Copyright Act, indicated by the "Taverne" license above, 


\section{Maastricht University}

Annemarie Nelen, Andries de Grip, Didier Fouarge

I s part-time employment beneficial for firm productivity?

$\mathrm{RM} / 11 / 007$

\section{METEOR}

Maastricht University School of Business and Economics

Maastricht Research School of Economics

of Technology and Organization

\section{P.O. Box 616}

NL - 6200 MD Maastricht

The Netherlands 


\title{
IS PART-TIME EMPLOYMENT BENEFICIAL FOR FIRM PRODUCTIVITY?
}

\author{
Annemarie Nelen $^{a *} \quad$ Andries De Grip $^{b} \quad$ Didier Fouarge $^{c}$ \\ ${ }^{a}$ Research Centre for Education and the Labour Market (ROA) \\ ${ }^{b}$ ROA, IZA \\ ${ }^{c} \mathrm{ROA}$
}

\begin{abstract}
This paper analyzes whether part-time employment is beneficial for firm productivity in the service sector. Using a unique dataset on the Dutch pharmacy sector that includes the work hours of all employees and a "hard" physical measure of firm productivity, we estimate a production function including heterogeneous employment shares based on work hours. We find that a larger part-time employment share leads to greater firm productivity. Additional data on the timing of labor demand show that part-time employment enables firms to allocate labor more efficiently. First, firms with part-time workers can bridge the gap between opening hours and a full-time work week. Second, we find that during opening hours part-time workers are scheduled differently than full-timers. For example, we find that part-time workers enable their full-time colleagues to take lunch breaks so that the firm can remain open during these times.
\end{abstract}

JEL codes: J24, L23, L25

Keywords: Heterogeneous labor, matched employer-employee data, allocation of labor, timing of labor demand.

${ }^{*}$ Corresponding author at ROA, Maastricht University, Tongersestraat 53, 6211LM Maastricht; tel. +31 4338836 47; fax +31 433884914 .

E-mail address: a.nelen@maastrichtuniversity.nl.

The authors are grateful to Daniële Bertrand-Cloodt, Arnaud Dupuy, Dan Hamermesh, Ben Kriechel, and seminar and conference participants at Maastricht University, SOLE 2009 in Boston, ESPE 2009 in Sevilla, LOPSI 2009 in Milan, EALE 2009 in Tallinn, and the IZA Summer School 2010 in Buch am Ammersee for useful discussions and comments on earlier versions of this paper. We thank Sander Dijksman for collecting parts of the data. 


\section{Introduction}

Service sectors often employ high rates of part-time employment. This is somewhat surprising since the human capital theory predicts part-time workers to be less productive than full-time workers. Research on the part-time pay penalty confirms this prediction (e.g., Iranzo, Schivardi, and Tosetti 2008; Ilmakunnas and Maliranta 2005). Nevertheless, some studies on part-time labor demand suggested that part-time employment might be beneficial at the firm level if, for example, operating hours exceed the full-time work week or when firms face fluctuations in customer demand (e.g., Delsen 2006; Owen 1978).

The aim of this paper is to analyze whether part-time employment is beneficial for firm productivity in service sector firms. For this purpose, we estimate a production function including heterogeneous employment shares (cf. Dearden, Reed, and Van Reenen 2006; Ilmakunnas and Maliranta 2005; Hellerstein, Neumark, and Troske 1999) based on employees' work hours.

Identification of the relation between part-time employment and firm productivity requires at least three specific features of the data: (1) a homogeneous sector in terms of capital use and a homogeneous workforce in terms of education level, (2) information on the work hours of all employees within firms, and (3) a "hard" physical or monetary measure of productivity. We use a unique matched employer-employee dataset on Dutch pharmacies that fulfills all three requirements and that can be considered characteristic of service sector firms whose openings hours exceed the full-time work week. Our analyses focus on the core workers (Osterman 2000, 1994), that is, pharmacy assistants, who account for $70 \%$ of total employment, measured in full-time equivalents (FTEs). All pharmacy assistants have the same educational background (level and field) required by law to be employed in their profession. Administrative data on the work hours of all employees in the sector enable us to construct firms' part-time and full-time 
labor shares based on work hours. Moreover, the number of prescription lines delivered to customers serves as a "hard" firm-level productivity measure. ${ }^{1}$

Other studies dealing with the relation between part-time employment and firm productivity have merely included a dummy variable to indicate the existence or importance of part-time employment (Arvanitis 2005) or were restricted to subjective productivity measures (Pérotin and Robinson 2000). Our dataset enables us to more precisely analyze whether part-time employment is beneficial for firm productivity. We find that firms with a large part-time employment share are more productive than firms with a large full-time employment share. Internal instrumental variable (IIV) analysis shows that our findings can be interpreted in a causal manner: A larger part-time employment share leads to greater firm productivity. Additional data on the timing of labor demand enable us to thoroughly examine possible allocation efficiencies provided by the use of part-time employment. We show that firms with high shares of part-time workers can bridge the gap between opening hours and a full-time work week. Moreover, we show that part-time workers are allocated differently than full-time workers. In particular, we find that part-time workers enable their full-time colleagues to take lunch breaks so that the firm can remain open during these times.

This paper is organized as follows: The next section briefly reviews related literature. Section 3 presents the empirical strategy. Section 4 describes the data and presents some sample statistics. Section 5 reports the results and presents robustness checks. Section 6 uses data on the timing of part-time labor demand to determine why part-time employment could be beneficial for firm productivity. Section 7 discusses the results in the context of quasi-fixed costs. Section 8 concludes the paper.

\footnotetext{
${ }^{1}$ Section 4 explains how registered medicines can be acquired in the Netherlands.
} 


\section{Related literature}

Although production function studies have included heterogeneous employment shares based on skill level, age, and/or gender (e.g., Iranzo, Schivardi, and Tosetti 2008; Ilmakunnas and Maliranta 2005), they implicitly assumed that part-time and full-time workers are equally productive in the hours they work. This is in sharp contrast to studies dealing with the effect of part-time employment on hourly wages. Relying on the assumption that wages reflect productivity, most studies found part-time workers to be less productive than full-timers in the hours they work (e.g., Hirsch 2005; Baffoe-Bonnie 2004; Aaronson and French 2004; Ermisch and Wright 1993). One exception is Manning and Petrongolo (2008), who found that including information on workers' occupations almost fully closes the gap between the hourly wages of part-time and full-time workers.

Apart from these individual productivity effects, part-time employment can also affect firm productivity through allocation efficiencies. Explanations for such firm-level productivity advantages in employing part-time workers can be found in the literature on part-time labor demand. This stream of literature describes several scenarios in which the demand for part-time employment is relatively high. Owen (1978) argued that firms employ part-time labor to avoid hiring overlapping shifts of full-time workers in industries where operating hours exceed the full-time 40-hour work week. Furthermore, Owen hypothesized that employers will use part-timers when there are fluctuations in demand. The author's results indeed show that the relative demand for part-time labor is higher in industries with an uneven distribution of temporal service demands, than in other industries. Mabert and Showalter (1990) also argued that the introduction of parttime employment implies efficiency gains in service sector firms that face fluctuations in customer demand because of the accompanying reduction in the number of hours during 
which workers are inactive due to lack of demand. These scenarios suggest allocation efficiency due to part-time employment.

However, research on the effect of part-time work on firm productivity is scarce and has mainly been limited to the inclusion of a part-time dummy for the presence or importance of part-time employment in firms. ${ }^{2}$ Arvanitis (2005) constructed a dummy variable to indicate whether part-time work is important within a firm. The author found a negative relation between the importance of part-time work and sales per FTE. Whereas Pérotin and Robinson (2000) included a variable measuring the fraction of part-time employment in their analyses, their dataset is restricted to subjective productivity measures. The authors did not find a significant relation between the proportion of part-time employment and managers' self-assessed labor productivity. ${ }^{3}$

\section{Empirical approach}

Our approach is inspired by three papers that modeled the productivity effects of different employment shares (Dearden, Reed, and Van Reenen 2006; Ilmakunnas and Maliranta 2005; Hellerstein, Neumark, and Troske 1999). ${ }^{4}$ The approach assumes that different types of employees are perfect substitutes but can have different marginal productivities. The sector under scrutiny, the Dutch pharmacy sector (see Section 4), employs

\footnotetext{
${ }^{2}$ One exception is a French study by Roux (2007) that examined the effect of part-time labor shares relative to full-time labor shares on firms' value added. However, it did not focus on a homogeneous workforce, which complicates identification of the part-time employment effect. Moreover, the reliability of value added as a productivity measure is questionable in labor-intensive sectors.

${ }^{3}$ Whereas our study is the first to examine possible productivity differences between part-time and full-time work hours, there exists literature on the differences between standard and overtime hours. Most of these studies used data at the industry level (e.g., Craine 1973; Feldstein 1967). As criticized by Leslie and Wise (1980), it is difficult to interpret these results, since the coefficient for the average work week can reflect other differences between industries.

${ }^{4}$ Dearden, Reed, and Van Reenen (2006) allowed for productivity differentials by training participation, education, occupation, age, tenure, and gender. Ilmakunnas and Maliranta (2005) included employment shares based on age, level and field of education, and gender. Hellerstein, Neumark, and Troske (1999) distinguished employment shares by gender, race, marital status, age, education, and occupation.
} 
a homogeneous core workforce with respect to education and gender, which allows us to divide the workforce into three employment shares: part-time (PT) and full-time (FT) core workers and other employees (OE). With the latter as our reference group, and its productivity normalized to unity, the relative productivity of the part-time employment share equals $\gamma_{p t}$ and the relative productivity of the full-time employment share equals $\gamma_{f t}$. If the $\gamma^{\prime} s$ are larger than unity, the relevant employment share is more productive than the reference group of other employees. The quality-adjusted labor input is therefore

$$
L^{*}=L\left[1+\left(\gamma_{p t}-1\right) \frac{P T}{L}+\left(\gamma_{f t}-1\right) \frac{F T}{L}\right]
$$

Under the assumption that $\left(\gamma_{p t}-1\right) \frac{P T}{L}$ and $\left(\gamma_{f t}-1\right) \frac{F T}{L}$ are "small," we can simplify Equation 1 by the following approximation ${ }^{5}$ :

$$
\ln \left[1+\left(\gamma_{p t}-1\right) \frac{P T}{L}+\left(\gamma_{f t}-1\right) \frac{F T}{L}\right] \approx\left(\gamma_{p t}-1\right) \frac{P T}{L}+\left(\gamma_{f t}-1\right) \frac{F T}{L}
$$

The part-time and full-time employment shares are thereby directly included in a logform production function. Using the quality-adjusted labor input $\left(L^{*}\right)$, we write the Cobb-Douglas production function as follows ${ }^{6}$ :

$$
Y=A K^{\alpha} L^{* \beta}
$$

\footnotetext{
${ }^{5}$ Following Dearden, Reed, and Van Reenen (2006) and Ilmakunnas and Maliranta (2005), we make this assumption to simplify the estimation-and ordinary least squares (OLS) estimation is then possible. However, the assumption can be relaxed without affecting our main findings. Following Hellerstein, Neumark, and Troske (1999), we also estimate a nonlinear least squares model. The results are similar, with the productivity differential between firms' shares of part-time and full-time employees being statistically significant.

${ }^{6}$ Since we assume capital use to be homogeneous across firms and workers, we only have one production input, quality-adjusted labor, and cannot estimate a translog production function as Hellerstein, Neumark, and Troske (1999) did.
} 
where output $(Y)$ is a function of capital $K$ and quality-adjusted labor $L^{*}$. Taking the logs of terms and using the approximation in Equation 2, we have

$$
\ln (Y)=\ln (A)+\alpha \ln (K)+\beta \ln (L)+\beta\left(\gamma_{p t}-1\right) \frac{P T}{L}+\beta\left(\gamma_{f t}-1\right) \frac{F T}{L}
$$

We follow Ilmakunnas and Maliranta (2005) in allowing for deviations from constant returns to scale. When FTEs are used instead of the number of workers $L$, the production function becomes

$$
\begin{gathered}
\ln (Y)=\ln A+\alpha^{\prime} \ln (K)+\left(\alpha^{\prime}+\beta^{\prime}-1\right) \ln (F T E)+ \\
\beta^{\prime}\left(\gamma_{p t}^{\prime}-1\right) \frac{P T_{F T E}}{F T E}+\beta^{\prime}\left(\gamma_{f t}^{\prime}-1\right) \frac{F T_{F T E}}{F T E}
\end{gathered}
$$

where $P T_{F T E}$ and $F T_{F T E}$ denote the number of part-time and full-time FTEs per firm, respectively.

Contrary to the three studies mentioned above, our focus on one particular sector allows us to assume capital use is homogeneous across firms. Therefore, the following production function is estimated:

$$
\ln (Y)=\theta+\delta \ln \left(F T E_{i}\right)+\phi_{p t} p t_{i}+\phi_{f t} f t_{i}+\varepsilon_{i}
$$

where $p t_{i}$ and $f t_{i}$ denote firms' part-time and full-time employment shares as defined as $\frac{P T_{F T E}}{F T E}$ and $\frac{F T_{F T E}}{F T E}$, respectively. Moreover, $\theta$ is a constant term and includes $\ln A$ and $\alpha^{\prime}$, $\delta$ equals $\left(\alpha^{\prime}+\beta^{\prime}-1\right)$, and $\phi_{p t}$ and $\phi_{f t}$ denote $\beta^{\prime}\left(\gamma_{p t}^{\prime}-1\right)$ and $\beta^{\prime}\left(\gamma_{f t}^{\prime}-1\right)$, respectively. If $\phi_{p t}$ and $\phi_{f t}$ are larger than zero, results imply that firms' shares of core employees are more productive than their shares of other employees. If $\phi_{p t}$ is significantly larger than $\phi_{f t}$, firms with a large share of part-time workers will be, on average, more productive than firms with a large share of full-time workers. We do not interpret a significant difference between $\phi_{p t}$ and $\phi_{f t}$ as a marginal productivity difference between part-time 
and full-time workers because the coefficients could reflect allocation efficiencies due to part-time employment. In alternative specifications, the model also controls for worker, pharmacist, firm, and market characteristics (see Section 4).

Moreover, because of potential endogeneity of employment shares, we also perform an IIV analysis. Arellano and Bover (1995) and Arellano and Bond (1991) explained IIV estimation for panel data, and an implication of the model can be found in Black and Lynch (2001). The authors estimated a generalized method of moments model, combining a production function in differences and levels. They instrumented current values of capital, labor, and materials by lagged values of both the levels and the changes over time of capital, labor, materials, and outputs. The idea is that lagged values are assumed to be correlated with current values, but independent of the error term.

Because we do not have panel data, we are unable to estimate such a model. Nevertheless, the administrative data from which we retrieve the number of working hours are available for two years (see Section 4). Therefore, we instrument firms' part-time and full-time employment shares by their lagged values, that is, firms' shares two years earlier. Under the credible assumption that these lagged values are correlated with current values, but independent of the error term, this type of IIV will pick up (at least some of the) endogeneity. Because we do not have panel data, we cannot test whether lagged explanatory variables are independent of the error term.

\section{Data and descriptive statistics}

We use a unique matched employer-employee dataset of Dutch pharmacies that fulfills all requirements to identify the relation between part-time employment and firm productivity. This dataset includes two sources of information: (1) employee admin- 
istrative data ${ }^{7}$ and (2) an employer survey. The datasets are merged on the basis of a unique firm identifier. The employers from all 1,890 Dutch pharmacies were invited to participate in an employer survey in January 2008, with two reminders sent in February and March 2008. Our final sample consists of 236 firms. $^{8}$ Analyses related to the nonresponse show that our sample is selective with respect to a pharmacy's geographical location, but not with respect to the firm's other characteristics. ${ }^{9}$ Therefore, we include regional dummies in all analyses.

Dependent variable. Our dependent variable is firm productivity. This is measured in the employer survey by firms' numbers of prescription lines delivered to customers in 2007. ${ }^{10}$ Every prescription line refers to a particular medicine that has been prescribed by a family doctor. In the Netherlands, this is the only possible way to obtain registered medicines. There is a close link between the number of prescription lines and firm sales due to the fixed amount of 6.10 euros that pharmacies receive for each prescription line, and because pharmacies only have a small market share in the sale of non-registered medicines. ${ }^{11}$ The physical character of this productivity measure ensures a relatively "hard" measure of firm productivity (Ichniowski, Kochan, Levine, Olson, and Strauss 1996). Table 1 reports sample statistics of our employer-employee sample. On average,

\footnotetext{
${ }^{7}$ This dataset is provided by the pharmacy sector's pension fund (PMA) and contains information on all employed workers within the sector. The data are from January 2006 and 2008.

${ }^{8}$ The dataset consists of 260 firms; data cleaning eliminated 24 firms.

${ }^{9}$ Our sample is representative with respect to key variables in our analysis, namely, the number of prescription lines delivered in 2007 and the hours distribution within firms. Whereas in our sample the average pharmacy delivered 78,291 prescription lines, the average number of prescription lines over the 1,890 pharmacies equals 78,000 (data from SFK, an independent foundation that publishes key indicators for the pharmacy sector). Moreover, our sample is representative with respect to the distribution of work hours among pharmacy assistants and other employees.

${ }^{10}$ De Grip and Sieben (2005) used the same measure of productivity in their analyses on pharmacy assistant productivity.

${ }^{11}$ In the Netherlands, most non-registered medicines are bought in firms other than pharmacies: Commercial drugstores and supermarkets have a market share of $85 \%$ for non-registered medicines (data from IMS Health, http: //www.hbd.nl/view.cfm? page $_{i} d=4288$ ).
} 
firms delivered 78,291 $(\exp (11.21))$ prescription lines in 2007.

[Table 1 about here]

Explanatory variables. Our main variables of interest are firms' heterogeneous employment shares in terms of FTEs. Therefore, we need to know the number of work hours of all the workers within all the firms. Information on contractual work hours for pharmacy assistants and other support staff is available in the administrative dataset. Information about the work hours of pharmacists is available from the employer survey. With these data, we can distinguish between firms' shares of part-time core employees, full-time core employees, and other employees. We focus on the core workers, that is, pharmacy assistants, ${ }^{12}$ because of their homogeneity with respect to several characteristics. Pharmacy assistants all have the same educational background required by law (in terms of both level and field). Moreover, the population of pharmacy assistants is homogeneous with respect to gender, $99 \%$ being female. We compute firms' part-time and full-time (core) employment shares as follows: $p t_{i}=\frac{F T E_{i, p t}}{F T E_{i, t o t a l}}$ and $f t_{i}=\frac{F T E_{i, f t}}{F T E_{i, t o t a l}} \cdot 13$

The standard full-time work week in the pharmacy sector being 36 hours, we define part-time workers as pharmacy assistants with fewer than 24 contractual work hours, that is, fewer than three work days. This definition differs from the definitions of parttime work usually used in the literature on part-time employment. Although there is no generally agreed upon standard, definitions ranging from 30 to 35 hours a week are most common (e.g., Connolly and Gregory 2008; Manning and Petrongolo 2008). However, our definition is well suited within our context. The Netherlands is known for its large share of part-time employment. Moreover, the pharmacy sector employs almost exclusively female pharmacy assistants with less than full-time work hours. Within the

\footnotetext{
${ }^{12}$ Osterman $(2000,1994)$ defined these core workers as the largest group of non-supervisory, nonmanagerial workers in a firm who are directly involved in making the product or providing the service.

${ }^{13}$ Firms' share of other employees is constructed the same way: $o e_{i}=\frac{F T E_{i, o e}}{F T E_{i, t o t a l}}$.
} 
Netherlands as a whole, around 50\% of all working women work fewer than 24 hours. In the pharmacy sector, $42 \%$ work fewer than 24 hours a week. ${ }^{14}$ Figure 1 shows the distribution of the work hours of all core workers within the sample. Whereas working fewer than two days (16 hours) is uncommon in the sector, working part-time is not. The largest group of core workers works between 16 and 24 hours per week. Work weeks of 24 to 32 hours and 32 to 36 hours per week are also quite common in the pharmacy sector. A total of $20 \%$ of all pharmacy assistants work exactly 36 hours per week (not shown in Figure 1). Section 5.2 checks the robustness of our findings by using other definitions of part-time employment and by dividing the core workers into more employment shares.

[Figure 1 about here]

Table 1 reports the average sizes of firms' employment shares and shows that firms' parttime employment share is, on average, equal to 0.19 , and their full-time employment share is, on average, equal to 0.50 . This large difference between firms' part-time and full-time employment shares is due to measurement in FTEs. Together, core workers account for almost $70 \%$ of firms' total employment.

Apart from these core workers, pharmacies employ pharmacists and other support staff. Most important among the latter are assistants' support staff and student pharmacy assistants. Assistants' support staff help pharmacy assistants in activities related to the production process. Student pharmacy assistants are involved in a dual training track combining work and classroom education. ${ }^{15}$ As can be seen in Table 1 , the other

\footnotetext{
${ }^{14}$ The difference in the percentage of part-timers working is due to a larger percentage of Dutch women (compared to Dutch pharmacy assistants) working in jobs with fewer than 16 hours a week (data from OSA-Labour Supply Panel 2006).

${ }^{15}$ Due to the involvement of all employment types in the primary production process, all employees in the sector are substitutes.
} 
employees altogether account for $31 \%$ of firms' total employment.

Control variables. Since firm productivity can also be influenced by worker, pharmacist, firm, and market characteristics, we control for such confounders. We include the total number of firms' employees, in FTEs, to take into account deviations from constant returns to scale. On average, firms' total number of FTEs equals 9.9. ${ }^{16}$ Regarding worker characteristics, we include the average age and tenure of the core workers. This information is available from the administrative data covering all employees. Table 1 shows that assistants are on average 38 years old and have a firm tenure of slightly more than eight years. ${ }^{17}$ We include pharmacist tenure to control for productivity differences due to employers. On average, pharmacists have a tenure of almost 16 years. The firm characteristics we include in our analyses are pharmacy type (independent or not), newly founded firm (yes/no), number of opening hours, and variables related to possible inefficiencies in the firm's allocation of labor: a dummy variable equal to one when employers report excess labor, and zero otherwise, and a variable measuring absenteeism due to sick leave from the fraction of workers calling in sick during the last calendar year. These variables are constructed from the employer survey. Table 1 shows that $42 \%$ of pharmacies are characterized as independent firms. The rest cooperate with other pharmacies, either in terms of chains or franchises or as part of legalized partnerships. A total of $4 \%$ of the firms are newly founded. On average, pharmacies are open for around 50 hours a week, while the full-time work week for pharmacy assistants equals 36 hours. A total of $13 \%$ of the firms report excess labor. The average annual absentee rate is $4 \%$.

\footnotetext{
${ }^{16}$ Table 1 reports the logarithmic form because we use the log form in the analyses as well.

${ }^{17}$ Since the majority of assistants are female and career breaks are common, we include both age and tenure in the analyses. Since the correlation between age and tenure is $35 \%$, including both variables will not cause any problems in the estimations.
} 
Finally, we account for two market characteristics that can affect productivity: the demand for medicines in the neighborhood where the pharmacy is located and the local degree of competition. We measure demand for medicines by the percentage of elderly $(60+$ years old) living within the pharmacy's postal code (four digits) area. Table 1 shows that, on average, the percentage of elderly within a postal code equals $22 \%{ }^{18}$ The degree of competition is measured by the number of competitors within a radius of five kilometers. This is calculated as the distances between all the pharmacies in the sample and all the other pharmacies located in the same region on the basis of postal codes. ${ }^{19}$ Table 1 shows that the number of competitors differs considerably across firms. Although, on average, firms have around 10 competitors, some have no competitors. The pharmacy facing the most competition has 77 competitors within a radius of five kilometers.

\section{Results}

\subsection{Part-time employment and firm productivity}

Table 2 shows the estimation results of several specifications of our production function. Column (1) takes into account only the scale effect and the two employment shares. The difference between the coefficients of firms' shares of part-time and full-time employees $\left(\phi_{p t}-\phi_{f t}\right)$ equals 0.556 and is significant at the $1 \%$ level. This finding implies that firms with a large share of part-time employees are more productive than firms with a low share of part-time employees.

\footnotetext{
18 These data are from the online statistical database of Statistics Netherlands (CBS Statline).

${ }^{19}$ We use a standard Dutch regional classification (COROP). The Netherlands counts 40 COROP regions, and every COROP region has a central point (city) with a surrounding service area.
} 
[Table 2 about here]

Column (2) reports the regression results when including worker, pharmacist, and firm characteristics. The main results remain the same; however, the productivity differential is slightly smaller when including control variables. The finding that firms with a large share of part-time employees are more productive than firms with a large share of fulltime employees still holds at the $2 \%$ level. We do not report the control variables, since none of them are significant. The only exception is a dummy variable denoting whether the firm is newly founded. We find that newly founded firms are significantly less productive than older firms, which is in line with the literature on the impact of vintage on productivity (e.g., Jensen, McGuckin, and Stiroh 2001). The results given in Column (3) include a set of variables that indicate the demand and competition the pharmacy faces, as specified in Section 4. ${ }^{20}$ Again, the finding that firms with a large share of part-time employment are more productive than firms with a large share of full-time employment is unaffected by the inclusion of these market characteristics.

Column (4) reports the results of an IIV regression. ${ }^{21}$ Firms' part-time and fulltime employment shares are instrumented by their shares in January 2006, that is, two years earlier. The coefficient of firms' full-time employment share becomes insignificant. Nevertheless, the difference between firm's part-time and full-time employment shares remains significant. This suggests that we can interpret our results in a causal manner: A larger part-time employment share leads to greater firm productivity.

\footnotetext{
${ }^{20}$ These controls are not significant either. We tried several alternative specifications for the measures for demand and competition, such as the number of inhabitants within a postal code area, the number of competitors within a radius of 10 kilometers, and the degree of urbanization. However, these did not change the estimation results.

${ }^{21}$ Since the adjusted R-squared value is smaller in specification (3) than in (2), we choose specification (2) for this analysis. However, using specification (3) does not change our results.
} 


\subsection{Robustness checks}

This section presents a series of robustness checks that address two particularly important decisions made in the estimation of Equation 6: the definition of part-time employment and the division of core workers into two groups.

\subsubsection{The definition of part-time employment}

A first robustness analysis tests whether our estimation results change when using different thresholds for part-time employment. Figure 2 reports the coefficients of firms' part-time and full-time employment shares, as well as their confidence intervals, using definitions of part-time employment ranging from working fewer than 16 hours to fewer than 33 hours per week. ${ }^{22}$ Figure 2 shows several interesting findings: When a part-time work week is defined as less than 16 hours, that is, less than two days a week, the coefficients of firms' shares of part-time and full-time core workers are not significantly different from each other. This is due to the large confidence interval of the coefficient for firms' part-time employment share, which, in turn, may be due to the small variation in this variable across firms. On average, when part-time employment is defined as a work week of less than 16 hours, firms' part-time employment share equals $0.017 \%$ (with a standard deviation equal to 0.032). When part-time employment is defined as a work week of less than $h$ hours with $h=[16, \ldots, 20]$, the same line of reasoning holds: Despite a larger coefficient for firms' share of part-time employees compared to their share of full-time employees, the imprecision of the estimated coefficients results in an insignificant difference between the firms' part-time and full-time employment shares.

[Figure 2 about here]

${ }^{22}$ The analyses are comparable to those reported in Table 2, Column (3). 
Figure 2 shows that when part-time work is defined as a work week of less than 21 hours, the coefficient of the part-time employment share is significantly higher than that of the full-time employment share. This also holds when part-time work is defined as a work week shorter than 22, 23, or 24 hours. However, when we define part-time employment as a work week of less than $h$ hours with $h=[25, \ldots, 33]$, the coefficients of firms' part-time and full-time employment shares are not significantly different.

The robustness checks show that our finding is robust to a particular range of hours for defining part-time employment. When we use definitions of part-time employment that reflect larger jobs, our results suggest that firms that employ large shares of parttime employees are as productive as firms that employ large shares of full-time employees. This suggests that firms are not able to benefit from allocation efficiencies when a relatively large share of workers works at least 24 hours a week.

\subsubsection{More shares of core employees}

We also check the robustness of our results by distinguishing core workers in small, medium, and large part-time jobs and full-time jobs. We define the four groups as follows: Employees in small part-time jobs work fewer than 16 hours. Employees in medium-sized part-time jobs work between 16 and 24 hours per week. Large parttime jobs are jobs of 24 hours or more per week but fewer than 32 hours. Employees working 32 hours per week or more are defined as full-time workers. We compute the employment shares for these four groups of core workers and use, as previously, other employees as the reference group. Except for including two extra shares of employees, the estimation strategy remains the same. Table 3 reports the results.

As before, we compare the relative productivity of the different employment shares of core employees. Table 3 shows no significant coefficient for the share of firms' small 
part-time employment. ${ }^{23}$ The share of firms' medium part-time employment has the largest coefficient. Table 3 shows that the coefficient for the share of firms' large parttime employment is only weakly significant, and the size of the coefficient is much smaller than the size of the coefficient for firms' medium part-time employment share. Most important is the finding that the share of firms' medium part-time employment is significantly more productive than the share of firms' full-time employment (at the 3\% level). The finding that the coefficient of the share of firms' large part-time employment is only weakly significant supports the hypothesis mentioned in Section 5.2.1, that the number of work hours of these part-time workers is too large to be allocated as efficiently as for part-time workers with fewer work hours per week. From this robustness check, we conclude that firms especially benefit from a large share of part-time employees working between 16 and 24 hours per week.

[Table 3 about here]

In conclusion, our robustness analyses show that firms with a large part-time employment share are more productive than firms with a large full-time employment share. This appears to be due to the fraction of part-time employees working between 16 and 24 hours per week, suggesting that these part-time workers are allocated most efficiently.

\section{Why is part-time employment beneficial for firm pro- ductivity?}

Our finding that firms with a large share of part-time employment are more productive than firms with a large share of full-time employment could be due to allocation effi-

\footnotetext{
${ }^{23}$ Again, this is probably due to this variable's small value and small standard deviation, as explained in Section 5.2.1.
} 
ciency offered by part-time employment. If this is true, part-time workers do not have to be more productive than full-time workers in the hours they work, for the use of parttime work to increase productivity at the firm level. Especially in service sector firms, part-time employment can, for example, be used to bridge the gap between opening hours and contractual work hours. Such a gap is also observed in our data. On average, firms are open around 50 hours a week, whereas the full-time work week counts 36 hours (see Table 1).

A second argument for the beneficial allocation effects of part-time employment is related to fluctuations in customer demand during opening hours. Due to these fluctuations, part-time employment enables firms to cushion peak hours by deploying more workers during that time than during opening hours with lower customer demand. Whether part-time or full-time workers are deployed during peak hours can depend on their relative productivity. A third way in which part-time employees can provide allocation efficiencies is by bridging the lunch breaks of their full-time colleagues.

To gain more insight into the allocation efficiency of part-time employment, we use additional data on the timing of labor demand within the Dutch pharmacy sector. These data are provided by the administrator of a scheduling program that is used by almost half of all Dutch pharmacies. ${ }^{24}$ Therefore, we know the work schedules of all the employees of 900 pharmacies in January 2010. From this dataset, we construct for each week the firms' number of core employees working and the fraction of part-time core workers in each half-hour time slot. Based on this information, we examine possible weekly and daily allocation efficiencies. At the individual level, we also look at the correlations between the number of contractual work hours, on the one hand, and the

\footnotetext{
${ }^{24}$ This scheduling program is freely available online to Dutch pharmacies. It allows them to plan the work time of their employees and contains details on the positions of employees, their contractual work hours, and the time slots they are scheduled to work.
} 
number of work hours per day and the work days per week, on the other hand.

Table 4 shows the correlation between, on the one hand, workers' contractual work hours and, on the other hand, the number of hours worked per work day, as well as the number of work days per week and per month. The correlation coefficients in Table 4 show that the greater the number of contractual work hours, the more hours employees work per work day. Nevertheless, Table 4 also shows that it is not the case that part-time workers work one or two hours per day solely to cover the lunch break of a full-time colleague. The table also shows that longer contractual work hours significantly relate to more work days per week and per month. Part-time workers therefore work not only fewer hours per work day, but also fewer days per week (month). This implies that parttime workers are allocated differently than full-time employees. The following analyzes whether the different allocations of part-time and full-time employees result in weekly or daily allocation efficiencies or both.

[Insert Table 4 and Figure 3 around here]

Figure 3 shows the allocation of total labor and part-time employment over the days of the week. Total labor is measured by the number of half-hour time slots worked by all employees per day. We sum the number of half-hour time slots of all employees working in the firm on that day. The share of part-time employment is computed as the number of all time slots worked by part-time employees over the total number of time slots worked by all employees. 
Figure 3 shows small fluctuations in the total amount of labor deployed across days. $^{25}$ Moreover, there seem to be some fluctuations in the share of part-time employment. Especially on Wednesday and Friday, the share of part-time employment is smaller than on other days; however, this seems to be supply driven, since children below age 12 do not have classes on Wednesday afternoon and, additionally, children below age seven do not have classes on Friday afternoon. Altogether, we have to conclude that Figure 3 does not show a clear relation between total labor needed on a day and employers' use of part-time employment over the week.

[Insert Figure 4 around here]

Figure 4 shows the allocation of workers over the work day. As far as fluctuations in total labor needed reflect fluctuations in customer demand, we do not observe much fluctuation in customer demand in the sector. The only exception is a daily low point during lunch time (between 12:00 PM and 1:30 PM); however, this is more likely to reflect the necessity of a lunch break for full-timers than a low point in customer demand. To see whether part-time employees are used to bridge the lunch breaks of full-time workers, we distinguish between firms that deploy no core employees and firms that do deploy core employees during lunch time. Figure 4 shows the average number of core employees and the fraction of part-time core employees for the first week of January 2010 (averaged over all firms), ${ }^{26}$ as well as several features that suggest allocation efficiencies provided by part-time employees.

- For all time slots, the fraction of part-time employees is larger in firms where no core employees are deployed at some time between 12:00 PM and 1:30 PM.

\footnotetext{
${ }^{25}$ Only on Saturday there is a clear drop in total labor deployed due to a large number of firms that are closed that day; firms that are open are often only open in the morning.

${ }^{26}$ Figures based on the other weeks look similar.
} 
- In the sample of firms that deploy at least one core employee during lunch time (the "no lunch break" sample), the fraction of part-time employees is largest during lunch time. This suggests that part-time workers indeed bridge the lunch breaks of their full-time colleagues. Moreover, as Table 4 shows, it is not the case that part-time workers work for only one or two hours during the lunch break. Some part-time workers start in the morning and work until after lunch time, while others start before lunch and work until closing time. ${ }^{27}$

- As shown in Figure 3, the fraction of part-time core employees is smallest on Wednesdays and Fridays. More precisely, on these days, the fraction of part-time employees is smaller in the afternoon than in the morning. This is noticeable because on Wednesday and Friday, children below ages 12 and seven, respectively, do not have classes in the afternoon.

We conclude that the allocation of part-time and full-time workers is quite different. Part-time workers work fewer hours per work day, as well as fewer days per week (month) than full-timers. In particular, they seem to bridge the lunch breaks of their full-time colleagues. Deploying a large fraction of part-time employees therefore seems to increase allocation efficiency over the work day, which contributes to greater firm productivity.

\section{Discussion}

Our findings raise the question of why service sector firms do not employ solely parttime workers. We think the answer can be found in the literature on part-time labor

\footnotetext{
${ }^{27}$ The data used for our estimations in Section 5.1 do not include information on whether firms deploy core employees during lunch time. Therefore, we cannot estimate the productivity model separately for these two groups of firms.
} 
demand. Montgomery (1988) discussed the determinants of employer demand for parttime workers. The author argued that the combination of part-time and full-time employees within firms depends upon the relative cost of providing labor services for each type of labor. These relative labor costs are determined by three factors: (1) the relative productivity of part-timers and full-timers, (2) the relative wages of part-timers and fulltimers, and (3) quasi-fixed labor costs. There are no a priori reasons to assume that the productivity of part-time and full-time workers differs in the hours they work. ${ }^{28}$ Moreover, as in most other Dutch occupations, the hourly wages of part-time and full-time pharmacy assistants are similar (Euwals and Hogerbrugge 2004). Therefore, we focus this discussion on quasi-fixed labor costs. ${ }^{29}$ Oi (1962) demonstrated that firms bear quasi-fixed costs of labor. These consist of the administrative costs of supervising and maintaining records for each worker, costs related to searching for, hiring, and training new workers, and those components of benefits that are unrelated to hours worked. Higher quasi-fixed costs are expected to decrease the proportion of jobs going to parttimers. Owen (1978) gave other examples of quasi-fixed labor costs that can apply to the service sector, such as supervision, coordination, and communication costs. Since the number of employees increases due to the usage of part-time workers, supervisors must oversee more workers or increase the number of layers of supervision. Increased communication and coordination costs are especially relevant when part-time workers are used sequentially. In this case it is likely that two groups of workers are formed, with no obvious need for communication and coordination. Owen (1978) suggested the

\footnotetext{
${ }^{28}$ As described in Section 4, all core workers share the same educational field and level. Moreover, additional analyses on a representative employee survey among pharmacy assistants did not show any difference in training participation or training intensity between part-time and full-time employees.

${ }^{29}$ With respect to the relative wages of part-timers and full-timers, Montgomery (1988) referred to Rosen (1978), who showed that firm and job characteristics determine which wage-hour combination the firm chooses. Relative productivity may vary among industries. Owen (1978) referred to the following industry characteristics that may affect the relative productivity of part-timers and full-timers: the capital intensity of the industry, the degree to which demand varies predictably over the work week, and the lack of easy division of opening hours into shifts of standard length.
} 
use of a full-time worker, a full-time supervisor, and overlapping shifts as possible ways of dealing with such a situation.

Montgomery (1988) investigated which firm, job, and industry characteristics influence the existence of part-time employment and the percentage of the firms' total employment force that works part-time. The author's results indicate that quasi-fixed labor costs have a negative impact on the proportion of part-timers in a firm's workforce. $^{30}$

\section{Conclusion}

This paper analyzes whether part-time employment is beneficial for firm productivity. Our unique dataset allows analyses of heterogeneous labor shares based on employees' work hours on a "hard" measure of firm productivity. Using a production function with quality-adjusted labor, we divide firms' workforce into part-time and full-time core workers and other employees. Our focus on a particular occupation that employs almost exclusively women justifies our part-time definition of working fewer than 24 hours a week. We find that firms with a large share of part-time employees are more productive than firms with a large share of full-time employees. IIV analysis shows that our findings can be interpreted in a causal manner: A larger part-time employment share leads to greater firm productivity.

Furthermore, we find that the greater productivity of firms with a larger part-time employment share is probably due to allocation efficiencies. Additional data on the timing of labor demand show that part-time employees are allocated differently than full-time employees. Part-time workers work fewer hours per work day, and fewer days per week. We show that part-time employment increases allocation efficiency over work

\footnotetext{
${ }^{30}$ Our data do not include any information on quasi-fixed costs that enable us to analyze the relation between such costs and firms' shares of part-time employment and productivity.
} 
days. In particular, part-time workers are deployed in such a way that they can bridge the lunch breaks of their full-time colleagues.

Our results may also explain why we observe high fractions of part-time employment in most service sectors and almost no part-time employment in other sectors. In general, service sectors provide good conditions for exploiting the allocation efficiencies offered by part-time employees. In the retail sector, these conditions are opening hours that exceed the full-time work week and opening hours during lunch time. In other service sectors, such as restaurants and call centers, fluctuations in customer demand during the work day or work week could constitute such a condition. In both cases, allocation efficiencies of part-time employment can increase firm productivity in service sectors. 


\section{References}

Aaronson, D., And E. French (2004): "The Effect of Part-Time Work on Wages: Evidence from the Social Security Rules," Journal of Labor Economics, 22(2), 329 352.

Arellano, M., AND S. BOND (1991): "Some tests of specification for panel data: Monte Carlo evidence and an application to employment equations," The Review of Economic Studies, 58(2), 277-297.

Arellano, M., AND O. Bover (1995): "Another look at the instrumental variable estimation of error-components models," Journal of Econometrics, 68(1), 29-51.

ARVANitis, S. (2005): "Modes of labor flexibility at firm level: Are there any implications for performance and innovation? Evidence for the Swiss economy," Industrial and Corporate Change, 14(6), 993-1016.

BAFFOE-BONNIE, J. (2004): "Interindustry part-time and full-time wage differentials: regional and national analysis," Applied Economics, 36(2), 107-118.

BLACK, S., AND L. LYNCH (2001): "How to compete: the impact of workplace practices and information technology on productivity," Review of Economics and statistics, 83(3), 434-445.

Connolly, S., And M. Gregory (2008): “Moving Down: Women's Part-Time Work and Occupational Change in Britain 1991 2001.," Economic Journal, 118(526), F52 - F76.

CRAIne, R. (1973): "On the service flow from labour," The Review of Economic Studies, 40(1), 39-46.

DE GRIP, A., AND I. SIEBEN (2005): "The effects of human resource management on small firms' productivity and employees' wages," Applied Economics, 37(9), 10471054.

Dearden, L., H. Reed, and J. VAn ReEnen (2006): “The impact of training on productivity and wages: Evidence from British panel data," Oxford Bulletin of Economics and Statistics, 68(4), 397-421.

Delsen, L. E. (2006): Operating Hours and Working Time: A Survey of Capacity Utilisation and Employment in the European Union. Springer Press, New York.

ERMisch, J. F., And R. E. Wright (1993): "Wage Offers and Full-Time and PartTime Employment by British Women.," Journal of Human Resources, 28(1), 111133. 
Euwals, AND HogerbRUGGe (2004): "Explaining the growth of part-time employment Factors of supply and demand," Discussion paper.

FELDSTEIN, M. (1967): "Specification of the labour input in the aggregate production function,” The Review of Economic Studies, pp. 375-386.

Hellerstein, J. K., D. Neumark, and K. R. Troske (1999): “Wages, Productivity, and Worker Characteristics: Evidence from Plant-Level Production Functions and Wage Equations.," Journal of Labor Economics, 17(3), 409-446.

HiRsch, B. T. (2005): "Why do part-time workers earn less? The role of worker and job skills," Industrial and Labor Relations Review, 58(4), 525-551.

Ichniowski, C., T. A. Kochan, D. Levine, C. Olson, and G. Strauss (1996): "What works at work: Overview and assessment.," Industrial Relations, 35(3), 299333.

ILMAKUnNAS, P., AND M. MALIRANTA (2005): “Technology, Labour Characteristics and Wage-productivity Gaps.," Oxford Bulletin of Economics and Statistics, 67(5), p623-645.

Iranzo, S., F. Schivardi, And E. TosetTi (2008): "Skill Dispersion and Firm Productivity: An Analysis with Employer-Employee Matched Data," Journal of Labor Economics, 26(2), 247-285.

Jensen, J., R. McGuckin, And K. Stiroh (2001): "The impact of vintage and survival on productivity: evidence from cohorts of U.S. manufacturing plants.," The Review of Economics and Statistics, 83(2), 323-332.

LESLIE, D., AND J. WISE (1980): "The productivity of hours in UK manufacturing and production industries," The Economic Journal, 90(357), 74-84.

Mabert, V., And M. Showalter (1990): "Measuring the Impact of Part-Time Workers in Service Organisations," Journal of Operations Management, 9(2), 209-229.

Manning, A., And B. Petrongolo (2008): "The Part-Time Pay Penalty for Women in Britain.," Economic Journal, 118(526), F28 - F51.

Montgomery, M. (1988): "On the Determinants of Employer Demand for Part-Time Workers.," Review of Economics and Statistics, 70(1), 112-117.

OI, W. (1962): “Labor as a quasi-fixed factor,” The Journal of Political Economy, 70(6), $538-555$. 
Osterman, P. (1994): "How Common is Workplace Transformation and Who Adopts it?," Industrial and Labor Relations Review, 47(2), 173-188.

(2000): "Work Reorganization in an era of Restructuring: Trends in Diffusion and Effects on Employee Welfare.," Industrial and Labor Relations Review, 53(2), p179 - 196.

Owen, J. D. (1978): Working Hours: An Economic Analysis. Lexington, Canada: Toronto.

PÉrotin, V., And A. Robinson (2000): "Employee Participation and Equal Opportunities Practices: Productivity Effect and Potential Complementarities.," British Journal of Industrial Relations, 38(4), 557-583.

Rosen, S. (1978): “The Supply of Work Schedules and Employment," in Work Time and Employment. National Commission on Manpower Policy, Washington D.C.

Roux, S. (2007): "Les gains de la flexibilité d'emploi pour les entreprises : le travail à temps partiel et de courte durée.," Reflets et perspectives de la vie économique, XLVI 2007/2-3, 117-140. 
Table 1: Sample statistics of dependent and explanatory variables.

\begin{tabular}{lllll}
\hline \hline & Mean & Std. Dev. & Min & Max \\
$\begin{array}{l}\text { Dependent variable } \\
\text { Number of prescription lines }\end{array}$ & 11.21 & 0.38 & 8.89 & 11.98 \\
$\begin{array}{l}\text { Explanatory variables } \\
\text { Firms' part-time employment share in FTEs * }\end{array}$ & 0.19 & 0.11 & 0 & 0.51 \\
Firms' full-time employment share in FTEs * & 0.50 & 0.14 & 0.08 & 1.00 \\
Control variables & & & & \\
Firms' total number of FTEs (log) & 2.22 & 0.40 & 0.73 & 3.09 \\
Assistants' average age in years & 38.03 & 4.36 & 22.50 & 50 \\
Assistants' average firm tenure in years & 8.31 & 3.10 & 0.81 & 17.93 \\
Pharmacist tenure in years & 15.84 & 8.47 & 0 & 39 \\
Independent pharmacy (yes/no) & 0.42 & 0.50 & 0 & 1 \\
Number of opening hours per week & 49.87 & 12.25 & 6 & 168 \\
Excess labor (yes/no) & 0.13 & 0.33 & 0 & 1 \\
Absentee ratio & 0.04 & 0.04 & 0 & 0.30 \\
Newly founded firm & 0.04 & 0.19 & 0 & 1 \\
Percentage of elderly within postal code area & 0.22 & 0.07 & 0 & 0.60 \\
Number of competitors within a 5-km radius & 9.61 & 12.25 & 0 & 77 \\
\hline \hline
\end{tabular}

Note: * concerns pharmacy assistants only. Sample statistics are based on the final sample (236 pharmacies). 
Figure 1: Distribution of working hours.

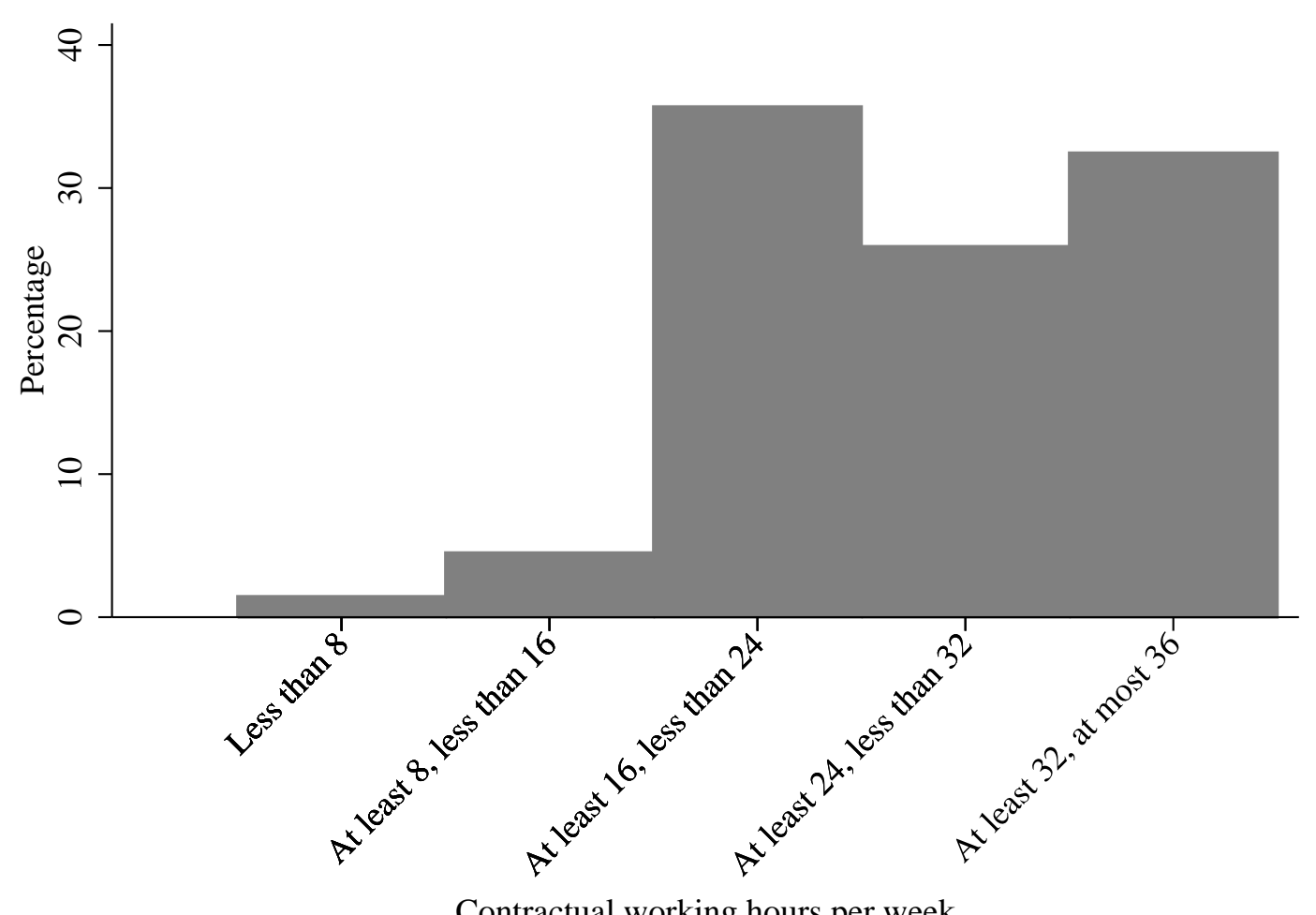

Contractual working hours per week 
Table 2: Estimation results of production functions with heterogeneous labor shares based on working hours.

\begin{tabular}{lllll}
\hline \hline Dep. Variable: Productivity $(\log )$ & $(1)$ & $(2)$ & $(3)$ & $(4)$ \\
Total amount of labor in FTEs (logs) & $0.740^{* * * *}$ & $0.693^{* * *}$ & $0.703^{* * *}$ & $0.639^{* * *}$ \\
& $(0.044)$ & $(0.046)$ & $(0.047)$ & $(0.048)$ \\
Firms' employment shares (other employees & are the reference group) & & \\
Firms' part-time employment share in FTEs & $0.946^{* * *}$ & $0.831^{* * *}$ & $0.881^{* * *}$ & $0.938^{* * *}$ \\
& $(0.182)$ & $(0.187)$ & $(0.196)$ & $(0.238)$ \\
Firms' full-time employment share in FTEs & $0.390^{* * *}$ & $0.424^{* * * *}$ & $0.412^{* * *}$ & 0.210 \\
& $(0.143)$ & $(0.143)$ & $(0.144)$ & $(0.186)$ \\
Constant & $9.169^{* * *}$ & $9.428^{* * *}$ & $9.387^{* * *}$ & $9.752^{* * *}$ \\
& $(0.157)$ & $(0.223)$ & $(0.233)$ & $(0.247)$ \\
\hline Worker, pharmacist, and firm characteristics & no & yes & yes & yes \\
External factors & no & no & yes & no \\
\hline Adjusted R squared & 0.556 & 0.581 & 0.579 & 0.519 \\
N & 236 & 236 & 236 & 236 \\
Model & OLS & OLS & OLS & IV \\
\hline Wald tests: PT share = FT share & 12.81 & 6.04 & 6.79 & 9.53 \\
Prob $>=\mathrm{F}$ & 0.0004 & 0.0148 & 0.0098 & 0.0020 \\
\hline \hline
\end{tabular}

Note: Standard errors in parentheses; $* \mathrm{p}<0.1, * * \mathrm{p}<0.05$, *** $\mathrm{p}<0.01$. Specification (1) includes region dummies. Specification (2) additionally includes assistants' average age and tenure, pharmacist tenure, the firm's number of opening hours per week, the firm's sick leave percentage, and dummy variables to indicate independent firms, excess labor, and newly founded firms. Specification (3), moreover, includes the percentage of elderly living in the firm's postal code area and the number of competitors within a radius of $5 \mathrm{~km}$. Specification (4) is an internal instrumental variable (IV) analysis. Firms' part-time and full-time employment shares are instrumented by their shares one year earlier (2006), and, for consistency, firms' total amount of labor is also constructed with 2006 values. 
Figure 2: Coefficients of firms' part-time and full-time employment shares using different definitions of part-time employment.

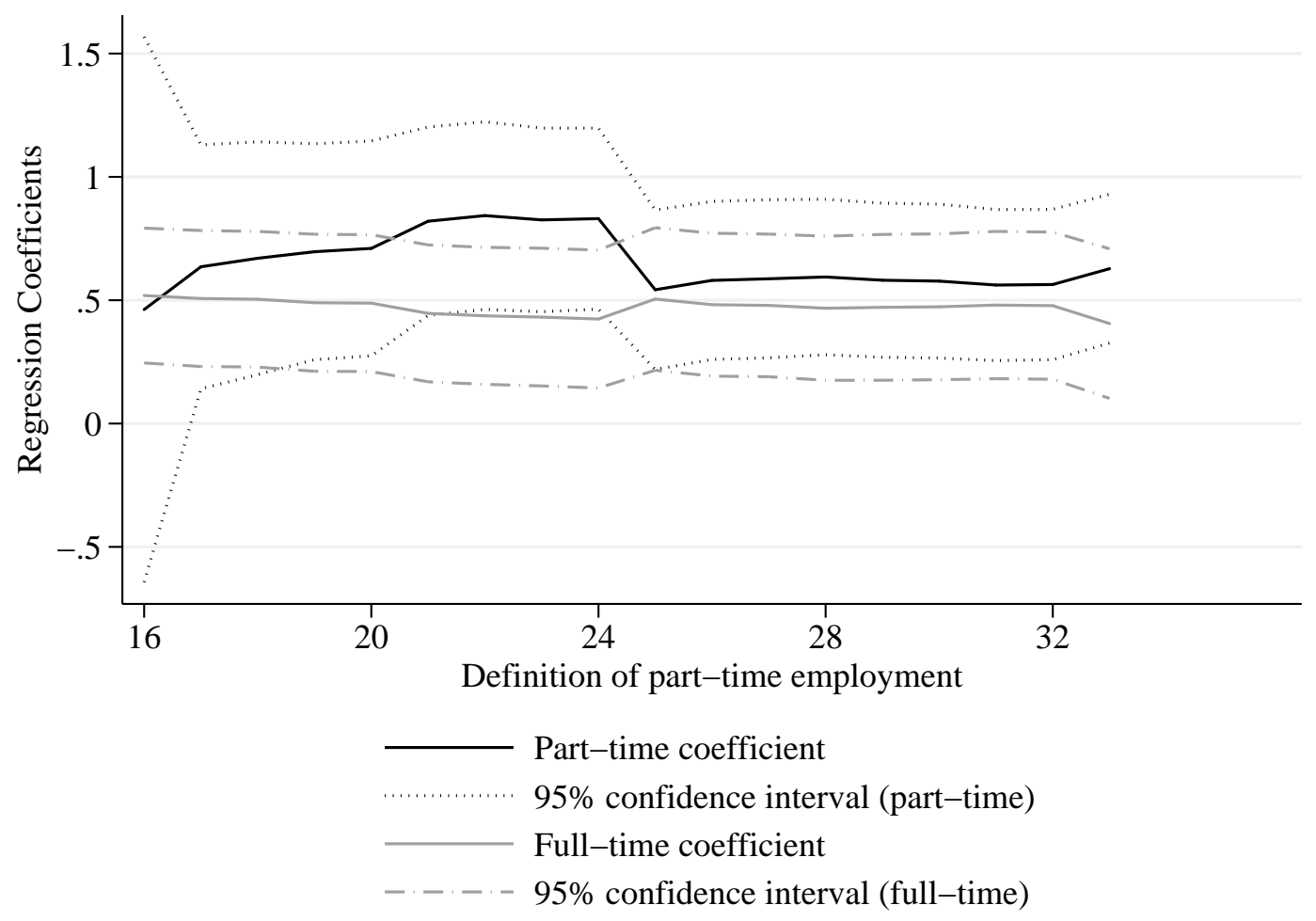

Note: This figure reports the coefficients of firms' part-time and full-time employment shares, as well as their confidence intervals, using definitions of part-time employment ranging from working fewer than 16 hours to fewer than 33 hours per week. The analyses are comparable to those reported in Column (2) of Table 2. 
Table 3: Estimation results of different shares of parttime employment on firm productivity.

Dep. Variable: Productivity (logs)

Total amount of labor in FTEs (logs)

$0.690 * * *$

Firms' small part-time employment share in FTEs

(0.046)

0.413

$(0.558)$

Firms' medium part-time employment share in FTEs

$0.866 * * *$

$(0.193)$

Firms' large part-time employment share in FTEs

$0.340 *$

(0.178)

Firms' full-time employment share in FTEs

$0.457 * * *$

(0.151)

Worker, pharmacist, and firm characteristics yes

Adjusted R squared 0.580

\begin{tabular}{lll}
$\mathrm{N}$ & & 236 \\
\hline Wald tests: & $\mathrm{F}(1,217)=$ & Prob $>\mathrm{F}$ \\
Medium PT share $=$ FT share & 5.18 & 0.0238 \\
\hline
\end{tabular}

Note: Standard errors in parentheses; * $\mathrm{p}<0.1$, ** $\mathrm{p}<0.05$, *** $\mathrm{p}<0.01$. The same controls are included as in Column (2), Table 2.

Model: OLS. 
Table 4: Correlations between contractual working hours and the usability of core employees.

\begin{tabular}{lll}
\hline \hline & $\begin{array}{l}\text { Contractual } \\
\text { working hours }\end{array}$ & $\begin{array}{l}\text { Part-time } \\
\text { worker }\end{array}$ \\
\hline Number of hours & 0.2180 & -0.3679 \\
per working day & $(0.000)$ & $(0.000)$ \\
Number of days & 0.7293 & -0.6605 \\
worked in week 1 & $(0.000)$ & $(0.000)$ \\
Number of days & 0.8294 & -0.5832 \\
worked in January & $(0.000)$ & $(0.000)$ \\
\hline \hline
\end{tabular}

Note: Based on the data of 8,257 core employees. 
Figure 3: Allocation of part-time employees over the week.

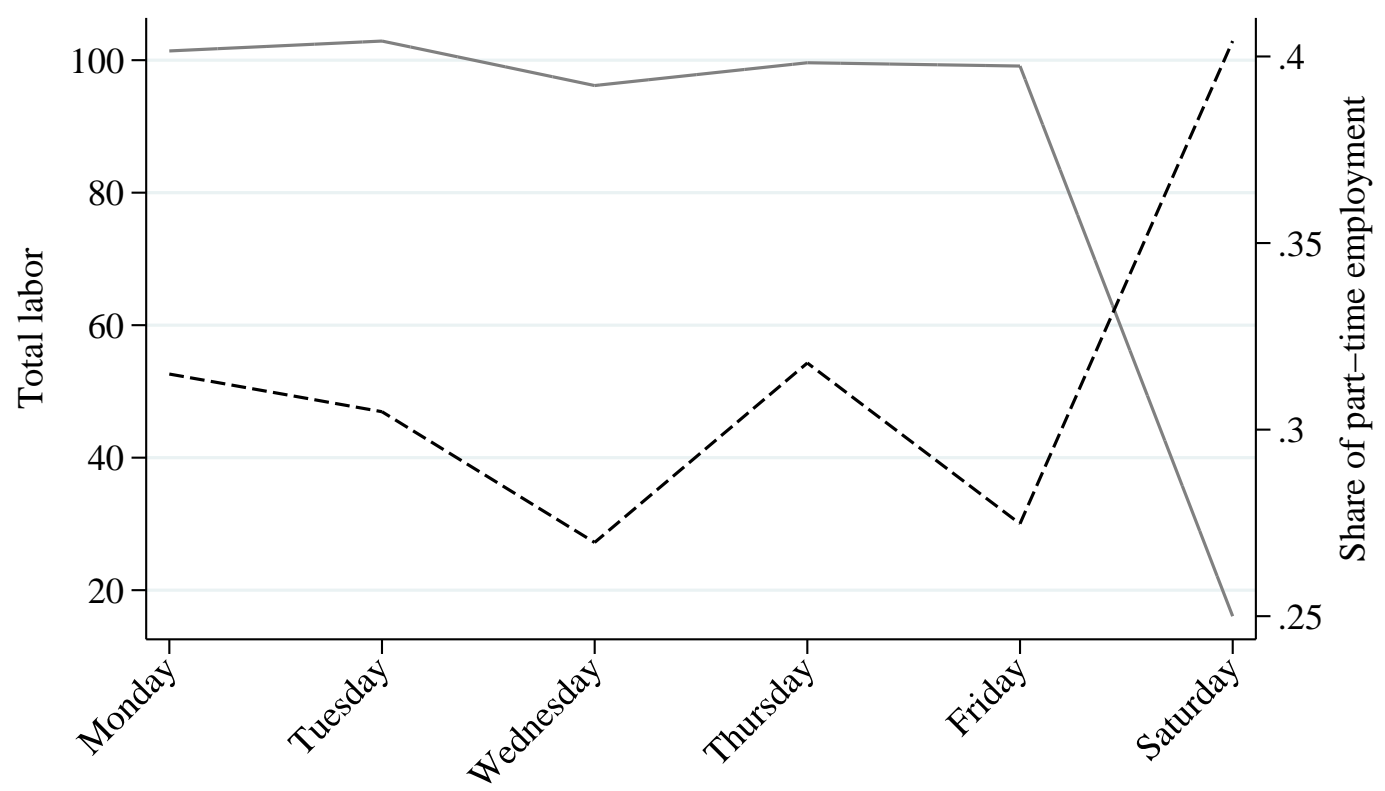

Day of the week

Total labor (in half an hour time slots)

Share of part-time employment 
Figure 4: Timing of labor demand — week 1.

(a) Monday

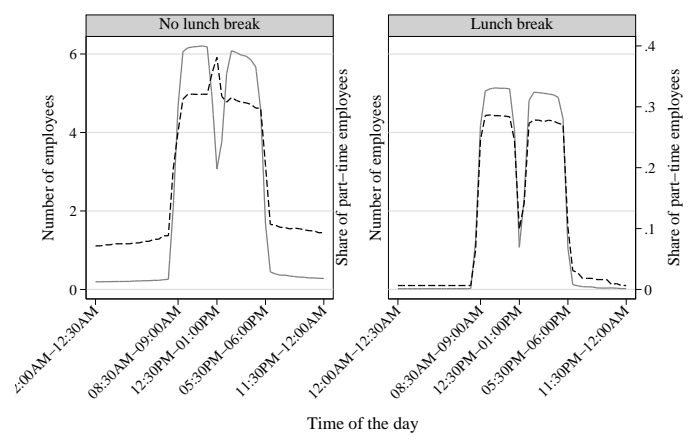

(c) Wednesday

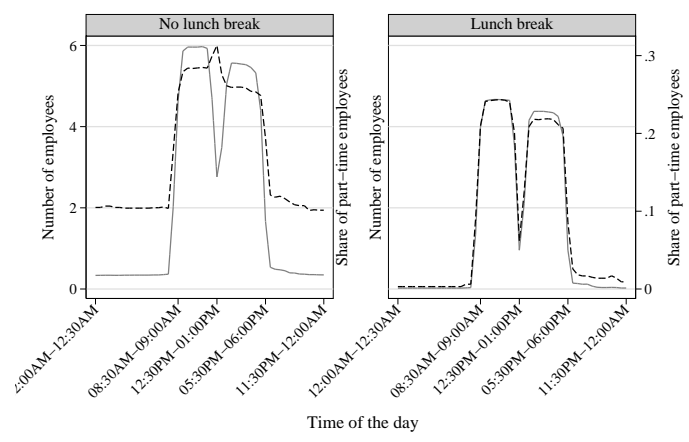

(e) Friday

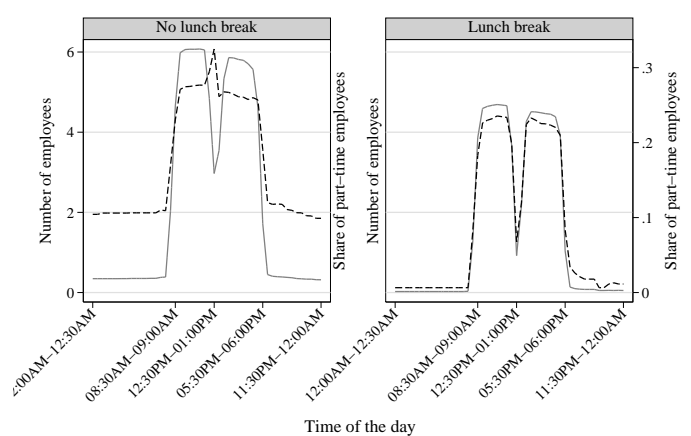

(b) Tuesday

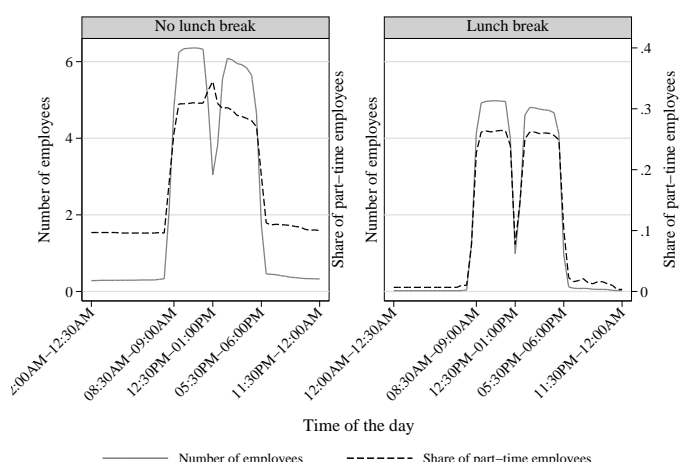

(d) Thursday

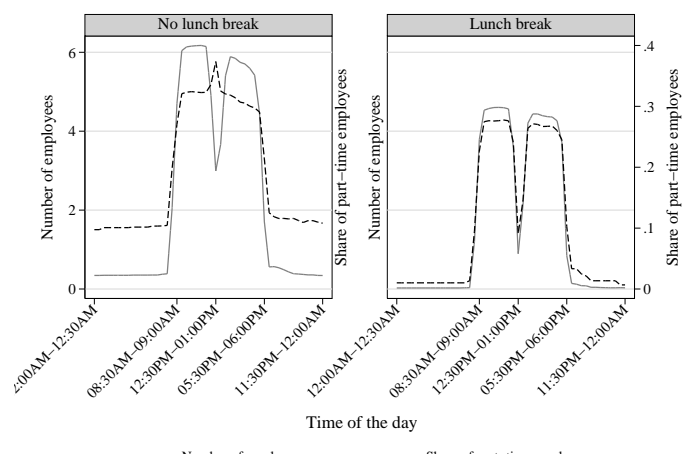

(f) Saturday

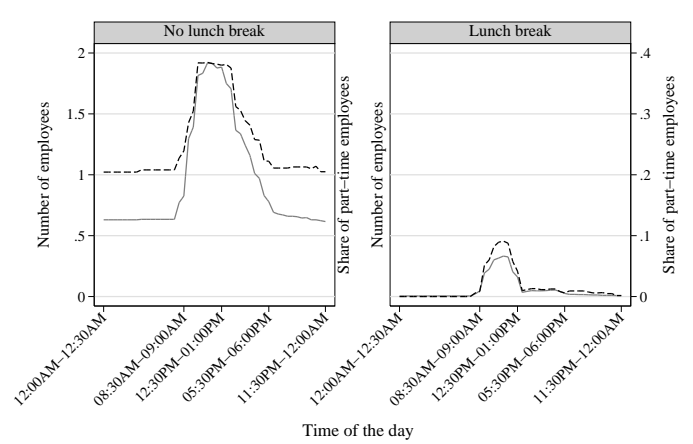

Time of the day

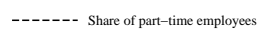

